Krieg, W. J. S. (1932). F. comp. Neurol. 55, i9.

Larsson, S. (1954). Acta physiol. scand. 32, Suppl. I 5.

Liebelt, R. A. \& Perry, J. H. (1967). In Handbook of Physiology. Alimentary Canal. Sect. 6, Vol. I. Chap. 2r. p. 27r [C. F. Code, editor]. Washington, D.C.: American Physiological Society.

MacLean, P. D. (1949). Psychosom. Med. I1, $33^{8}$.

Mayer, J. \& Barnett, R. J. (1955). Science, N.Y. 121, 599.

Morgane, D. J. (196ra). \%. comp. Neurol. II7, 1.

Morgane, D. J. (т 96rb). Am. F. Physiol. 201, 420.

Morgane, P. J. (1969). Ann. N.Y. Acad. Sci. 157, 806.

Morgane, P. J. \& Kosman, A. J. (I959). Am. J. Physiol. 197, 58.

Morrison, S. D. \& Mayer, J. (1957). Am. F. Physiol. r04, 247.

Olds, J. (1958). F. comp. Physiol. 51, 675.

Sterman, M. B., Wyrwicka, W. \& Roth, S. (1969). Ann. N.Y. Acad. Sci. 157, 723.

Stevenson, J. A. F. (1969). Ann. N.Y. Acad. Sci. 157, 1069.

Tarttelin, M. F. (1968). F. Physiol., Lond. 195, 29P.

Tarttelin, M. F. (r969). A physiological investigation of the medial hypothalamus of sheep with special reference to food and water intake. PhD Thesis, University of London.

Tarttelin, M. F. \& Bell, F. R. (1968). In Proceedings of the Third International Conference on regulation of food and water intake. Haverford, $\mathrm{Pa}$ (mimeo.).

Wagner, J. W. \& de Groot, J. (1962). Anat. Rec. 142, 332.

Wagner, J. W. \& de Groot, J. (I963). Am. F. Physiol. 204, 483 .

Wyrwicka, W. \& Dobrzecka, C. (1960). Science, N.Y. 132, 805.

\title{
Physiological mechanisms for the regulation of energy balance
}

By G. R. Hervey, Department of Physiology, School of Medicine, University of Leeds, Leeds $L_{2} S_{9} N L$

No one will dispute that whether or not an animal or man is eating at a particular moment depends upon many factors. In this sense, control of food intake is highly multifactorial. It is, however, sometimes valuable to isolate a single factor from the multitude which govern real events, even though this seems to lead to a theoretical abstraction. This paper will be concerned only with regulation of food intake in relation to energy balance; that is, with the factors which regulate energy ingested in correspondence with energy expended.

A theoretical need for regulation of energy balance arises from the conservation of energy. It seems inescapable that:

energy intake of body = energy output from body $+\triangle$ energy in body.

This is so without regard to the important differences in thermodynamic level of the energy, which are - speaking teleologically - the whole point of energy exchange. Since energy stored in the body is, like food, in chemical form, predominantly fat, changes in its amount must be perceptible as changes in body-weight; more accurate measurement is of course possible by carcass analysis. Inasmuch as adult animals do not change greatly in body-weight and composition, it follows that their intake and output of energy must be equal within a calculable degree of precision. Bccause the energy store in the bodies of larger animals such as man is large compared with the energy turned over in a day - representative figures for a man could be 
100000 and $3000 \mathrm{kcal}$ respectively - there is no need for intake and output of energy to be equal over periods such as a day. Experimentally no correspondence is found. On the other hand, because the maximum possible change in the store is small compared with the energy turnover of an adult lifetime, over long periods it would seem that energy intake and output must be equal within close limits; as a percentage of turnover, the permissible inequality is smaller the longer the period we consider. This theoretical need for very high long-term precision has been emphasized by numerous workers. Experimentally, there are obvious difficulties in measuring intake and output accurately for long periods but, in general, the theoretically inevitable near-equality has been confirmed in practice. The experiments of Widdowson, Edholm \& McCance (1954) and Edholm, Fletcher, Widdowson \& McCance (1955) illustrate transition from lack of any correlation between intake and output during a day, to near-equality over 2 weeks. Durnin (1961) has reviewed the timefactor in energy balance.

Since it follows from the conservation of energy and the chemical nature of the body's energy stores that body-weight and fat content depend on the precise balance between energy intake and output, abnormal weight and fat content must signify abnormal balance at some time. The mechanisms which control energy balance thus constitute the underlying physiology of obesity and also of anorexia, in the sense that they must have been deranged or unable to cope with a prevailing situation, when these conditions are found.

If some quantity remains nearly constant over long periods, although it is continually gaining from and losing to the outside world, there are several ways in which this may come about. If we take as example a tank that supplies some liquid to meet a variable demand and which is replenished from a supply, we can imagine several mechanisms which could result in the level of liquid in the tank remaining nearly constant (Fig. I). Variations and combinations of the systems shown can be imagined. The main point is that there are 'passive' systems, in which the physical arrangement of the components leads to a degree of constancy, and 'active' ones which incorporate a feedback regulator. It may be noted that 'load error' - a change in the steady state level of the liquid when there is a change in output demand - is characteristic of all the arrangements. We may expect it to be less in feedback systems, but its presence or absence is not diagnostic. Teleology should really have no place in scientific discussion, but it may be observed that all the arrangements except (d) are wasteful: control requires a throughput of liquid larger than the needs of the process itself.

If we look at the available data from animals, it is possible to find evidence for mechanisms of the 'passive' type. For example, the energy cost of walking at a set pace varies almost in proportion with the weight of the body; thus weight gain resulting from positive energy balance would increase expenditure, and this might re-establish balance. The well-known reduction of resting energy expenditure during fasting may be thought of in the same terms. Difficulties of scale arise if it is supposed that such passive mechanisms are entirely responsible for the long-term approximation of energy intake and output. The momentary rate of energy ex- 

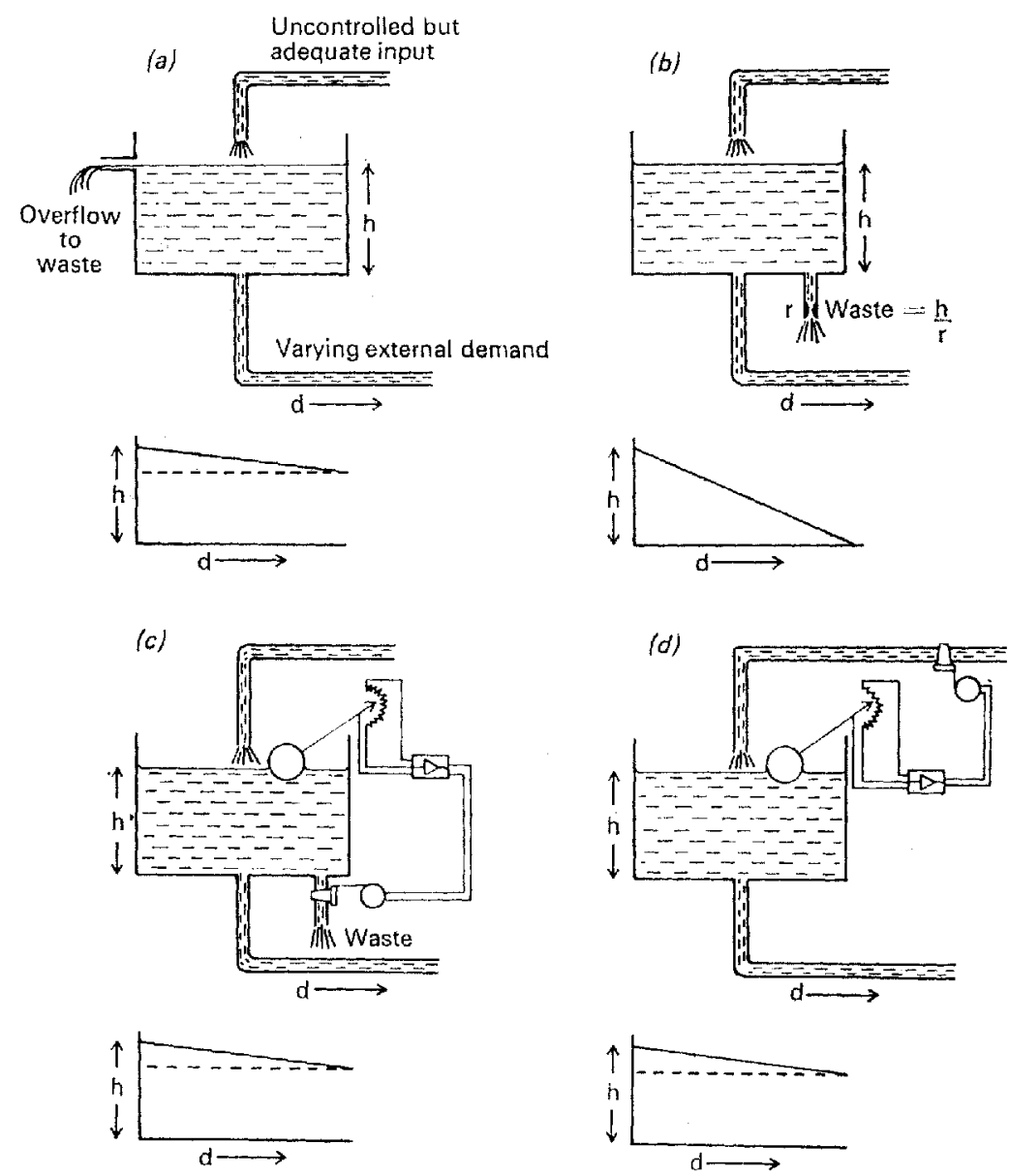

Fig. I. Mechanisms by which the level (h) of fluid in a tank, supplying a variable external demand (d) may be kept constant; (r) resistance to outflow. The control characteristic is shown below each diagram.

penditure in an individual may vary with the intensity of physical activity over a range of about $\mathrm{I}: 20$; energy expenditure per $24 \mathrm{~h}$ varies among individuals, even from an apparently uniform population as to age, sex etc., over a range of the order of from half to twice the mean value (Widdowson et al. I954). It seems likely that a passive mechanism which kept intake and output of energy as closely equal as they are found to be over this range would be extremely wasteful; it also would not permit what appear to be programmed variations in the level of the energy store, such as the gain of weight and fat which occurs in pregnancy.

On the other hand, there are classical experiments in the field which are difficult to explain without an 'active' feedback hypothesis. Among these, dietary calorie dilution and reinforcement experiments in rats (Adolph, 1947; Hervey, I $969 a$; Fig. 2), intragastric feeding experiments in dogs (Janowitz \& Hollander, 1955) and the 'sweet drink' experiments of Richter (1956) on the rat are particularly impressive. In the calorie dilution and concentration experiments, body fat does change in a way 

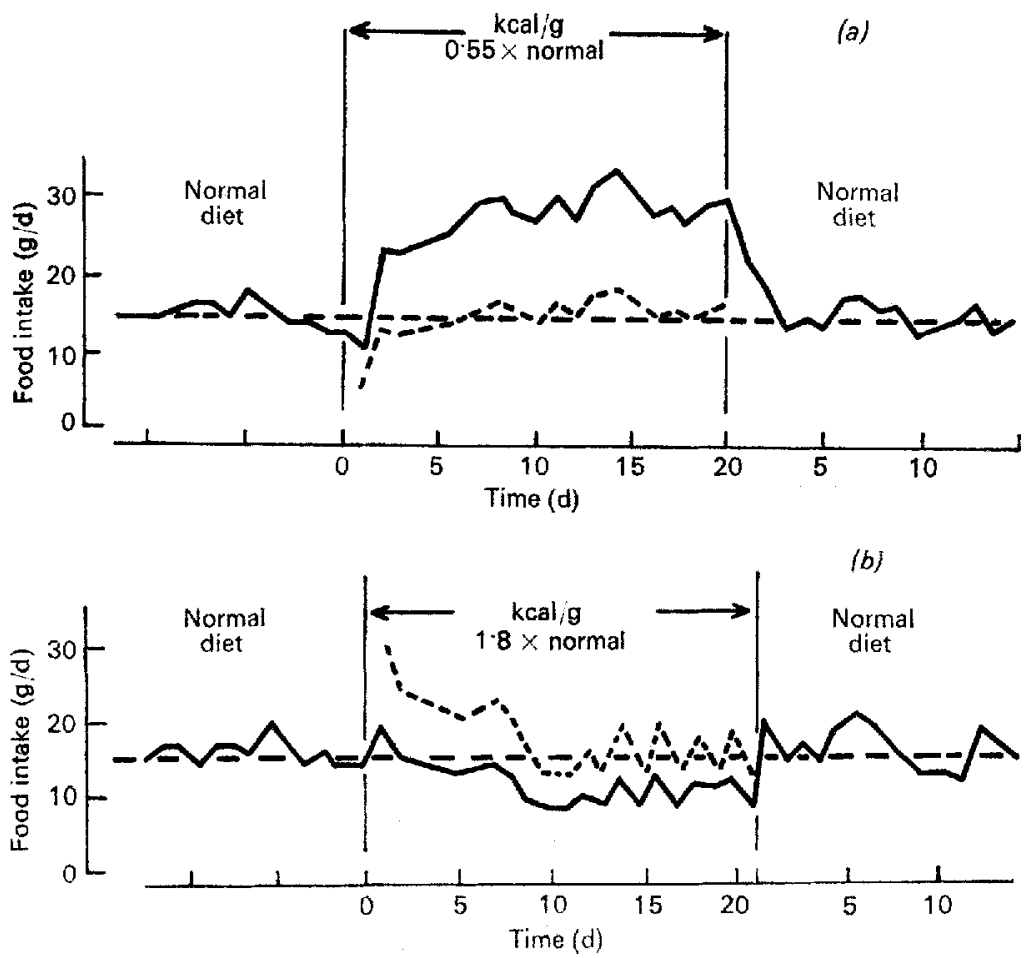

Fig. 2. Changes in weight of food eaten and in energy intake per $\mathrm{d}$ in adult female rats: $a$, on reducing the energy content per unit weight of diet; $b$, on increasing it. —_ weight of food eaten daily; - - energy content of food eaten, expressed in terms of equivalent weight of the original diet; _ - mean food intake in the initial period.

which can be interpreted as a load error, but as we have seen this is not diagnostic. Live body-weight, however, hardly changes, since the weight of the contents of the gastro-intestinal tract increases the more inert material is present: thus, the work of moving about can probably be excluded as a regulating factor here. It is difficult to see what could bring about the corrective changes in food intake in experiments such as these, other than a feedback regulation using some signal which indicated the current state of energy balance.

A feedback control system can be regarded as comprising a sensor, afferent pathway, controlling centre, efferent pathway and effector, (these may, of course, be replicated). There is much evidence suggesting that the greater part of the central control for energy balance is located in the hypothalamus. Experiments such as those referred to above suggest that adjustment of food intake is an important effector; this does not exclude the possibility that variation in energy output may play some part in the regulation. The reduction in energy expenditure in starvation may be in this category; so also may be the action of progesterone in certain circumstances (see below). The possibility of 'luxuskonsumption' - increased dissipation of energy following excess energy intake - has been raised from time to time, and is implicit in the recent report of Miller, Mumford \& Stock (1967) that the energy cost of a standardized activity is greater after absorption of excess calorie intake. 
If this mechanism is confirmed, it will be interesting to know how much excess energy can be burned off and, therefore, the possible quantitative contribution to control.

The nature of the sensor and the afferent pathway is a major problem. Three suggestions were made about 20 years ago: identifying respectively changes in plasma glucose concentration, in body temperature and in body fat content as the important quantity sensed (Brobeck, I948; Mayer, 1952, 1955; Kennedy, 1953). Other metabolites, for example amino acids and fatty acids in plasma, have been suggested more recently. If the long time-constant of the regulation and the increasing precision the longer the period studied are considered, the 'fat' theory seems to be the only one which will work, whatever its other difficulties. Changes in plasma glucose and body temperature are characteristically short-lived and restored by their own control mechanisms, and it seems likely that they are primarily related to the rate of energy turnover and other circumstances at the particular time. If these were the primary signals used to measure energy balance, the control system would require a long-term integrator of perfect accuracy (Kennedy, 1953). Inasmuch as conservation of energy requires that any difference between energy intake and output over any period must be associated with an exactly corresponding change in stored energy, which will then persist until an opposite balance occurs, the amount of fat in the body provides an integrated record of the total of all past gains and losses of energy. It is difficult to see what other physiological quantity could do this.

This is not to say that other information does not play a part. Most physiological

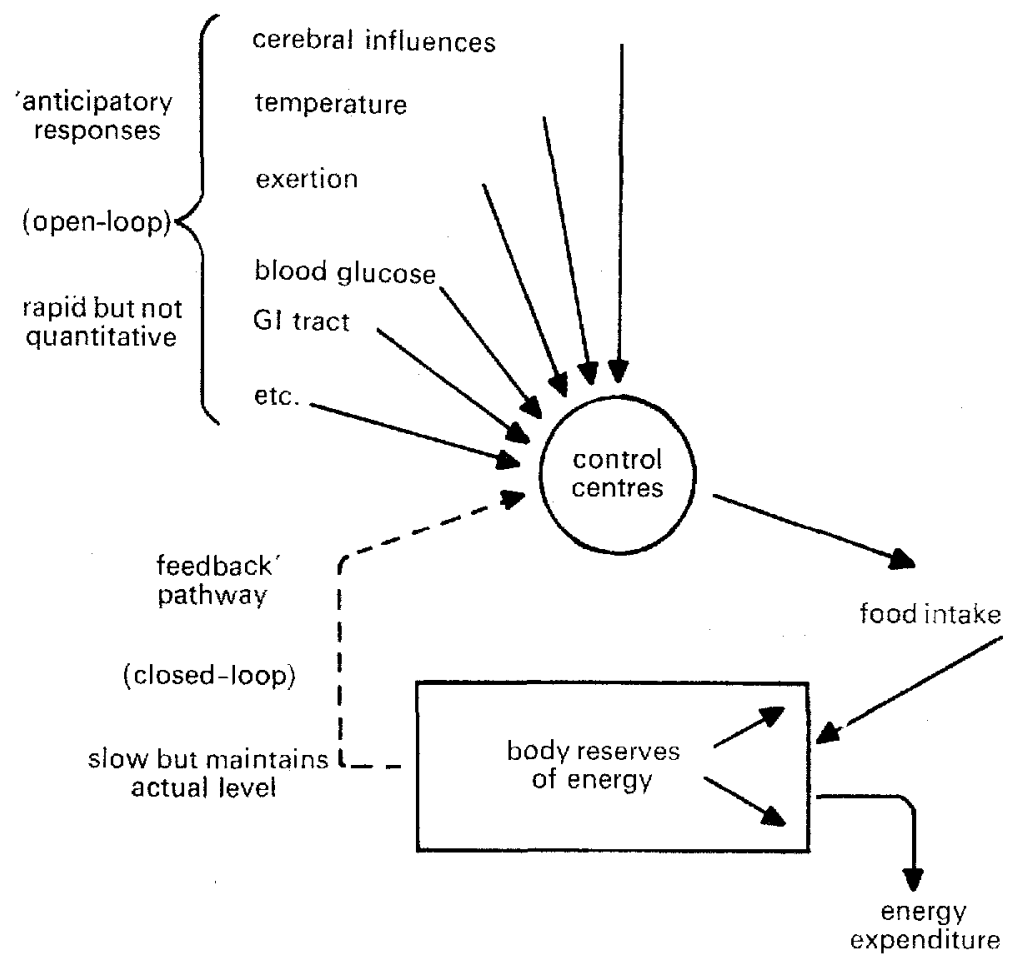

Fig. 3. Hypothetical organization of the regulation of energy balance. GI, gastro-intestinal tract. 


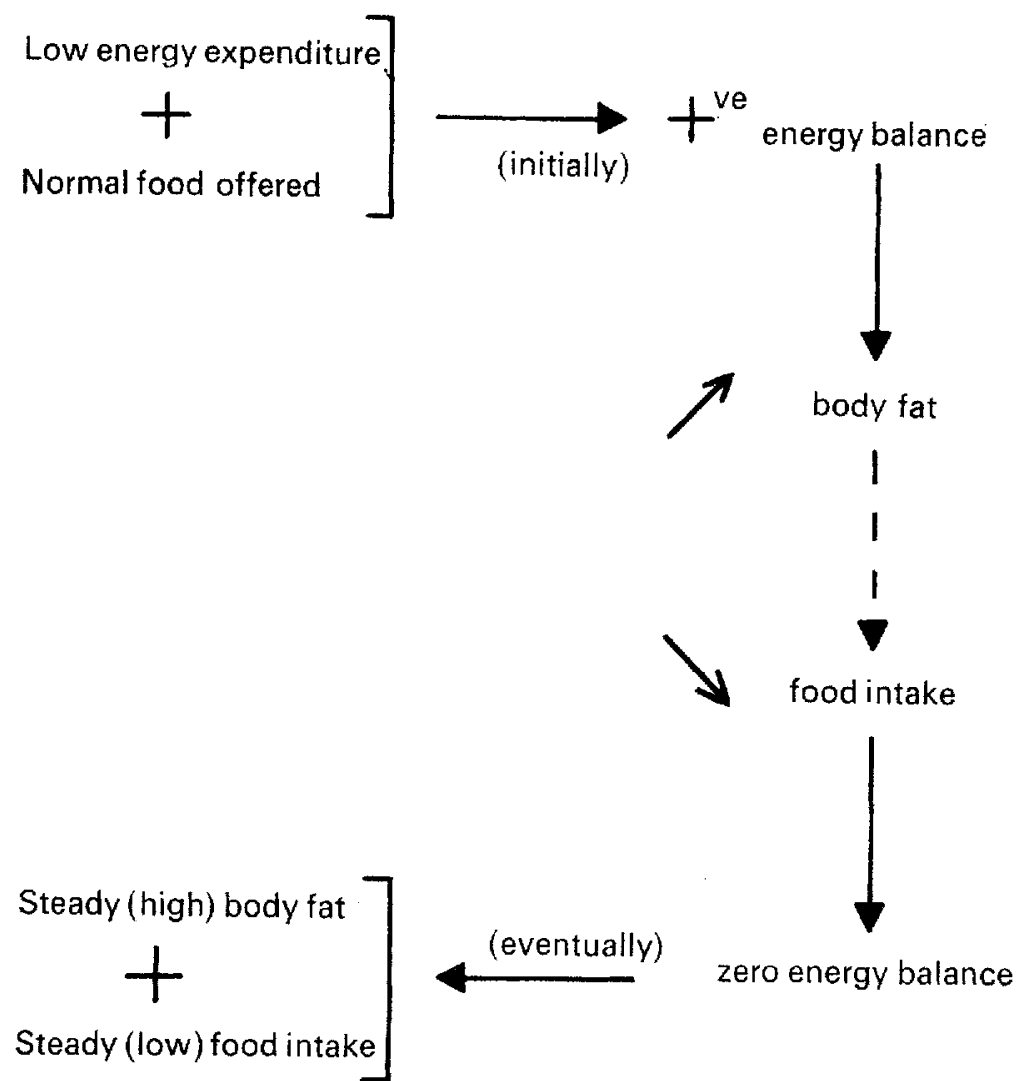

Fig. 4. 'Regulatory obesity': the sequence of events which, on the lipostatic hypothesis, may explain the combination of a lower than average intake of food with a higher than average bodyfat content. Sloping arrows denote increase or decrease respectively.

controls involve rate-of-change, or anticipatory, information as well as information about the actual level of the quantity controlled; in man-made control systems this is a well-known method of improving the response time and stability of the system. Fig. 3 shows a model for the regulation of energy balance which combines the wellknown short-term or rate signals with a hypothetical sensing of body energy reserves (Hervey, 1962).

A valuable feature of the concept of regulation of body fat content by a feedback control from the level of energy reserves is that it can make sense of the common clinical dilemma - perhaps first reported in Joseph's kine - posed by the existence of people who are fat but apparently eat little, and their converse. If, in the wide range of variation in $24 \mathrm{~h}$ energy expenditure encountered, an individual's expenditure is below the average, and he is offered and accepts the food intake appropriate to an average person, he must gain fat (Fig. 4). If the accumulation of fat does lead to an increasingly strong feedback signal which inhibits food intake, a steady state would be reached when enough fat had accumulated to provide a strong enough inhibitory signal to hold food intake down to equal the low energy expenditure. The above-normal fat content is the 'load error' of the system; it and the low food intake are causally related, and not paradoxical. It is more difficult to measure 
$24 \mathrm{~h}$ energy expenditure than 'basal' metabolic rate, but there are some grounds for thinking that low 24 h energy turnover is characteristic of obese people.

The obvious difficulty attached to the idea that body fat provides the information for the regulation of energy balance is that, whereas the hypothalamus is known to be sensitive to the glucose concentration and temperature of the blood, there is no known mechanism which measures body fat and transmits the result to the hypothalamus. Some years ago experiments with parabiotic rats (Hervey, I959) suggested that information used by the hypothalamus in regulating energy balance may travel to it by the blood-stream. Some known hormones and allied substances, particularly steroids, do alter body-fat content. The action of progesterone has been most thoroughly investigated (Hervey \& Hervey, r967). There is good evidence that this hormone is responsible for the gain of weight which occurs in most female mammals in early pregnancy (Dewar, 1957; Hervey, Hervey \& Berry, I967). In the rat in ordinary circumstances this effect appears to be brought about mainly or entirely by increased food intake (Hervey \& Hervey, r964). In rats with access to running drums, some energy is saved by reduction in the amount of running (Hervey, I964). If food intake is restricted to the control level, weight and fat are still gained; presumably energy expenditure is then reduced, but this is still under study (Hervey \& Hervey, rg69). The integration of these changes, and the way in which the same end-result is attained by different means according to the prevailing circumstances, suggest that the hormone is influencing the central regulatory mechanism, rather than feeding, motor or other mechanisms as such. Some other progestational steroids share this action of progesterone. Oestradiol has an opposite effect, and reduces body fat; there are some grounds for suggesting that, in the rat, progesterone may act by decreasing the secretion of oestrogen through a centrally mediated effect (Hervey \& Hervey, I965; I966; Hervey, Hervey, Hutchinson \& Jeffery, 1969).

If progesterone or other steroids do act on the central regulation for energy balance, the action is equivalent to 'resetting' a thermostat or similar device to a new 'set level'. This implies changing the sum of the inputs to the control mechanism. If the steroids have such an effect, a possibility arises that they are adding to a pre-existing input of basically similar nature. It is possible to suggest, speculatively, how steroids could provide a measurement of body fat for the hypothalamus (Hervey, I $969 b$ ). The 'dilution hypothesis' suggests that, if a substance which has a high fat:water solubility partition coefficient is present in the body in constant amount, its concentration in the water phase of the body will vary inversely with the amount of fat present and so could provide an indication of this. If the amount of fat in the body fell, and if the substance acted, like progesterone, as a stimulus for the attainment of a more positive energy balance, then a negative feedback regulation for body fat would exist.

Long-term phenomena and closed-loop control systems both raise difficulties for experimental investigation, particularly when in combination. Though the present lack of evidence may serve as some excuse for speculation, one can only conclude by emphasizing the great need for more evidence in this field. 
Much of the personal work referred to was supported by a grant from the Medical Research Council.

Figs. 2, 3 and 4 in this paper are taken from Nature, Lond. 222, 629 and are reproduced with the permission of the Editor of Nature.

\title{
REFERENCES
}

Adolph, E. F. (1947). Am. F. Physiol. 151, 1 10.

Brobeck, J. R. (1948). Yale J. Biol. Med, 20, 545.

Dewar, A. D. (1957). F. Endocr. 15, 2 16.

Dumin, J. G. V. A. (1961). F. Physiol., Lond. 156, 294.

Edholm, O. G., Fletcher, J. G., Widdowson, E. M. \& McCance, R. A. (I955). Br. Y. Nutr. 9, 286.

Hervey, E. \& Hervey, G. R. (1966). I. Physiol., Lond. r87, 44P.

Hervey, E. \& Hervey, G. R. (1967). F. Endocr. 37, 36r.

Hervey, E. \& Hervey, G. R. (1969). F. Physiol., Lond. 200, 118 P.

Hervey, E., Hervey, G. R. \& Berry, P. M. (1967). F. Endocr. 38, iv.

Hervey, E., Hervey, G. R., Hutchinson, I. \& Jeffery, J. d'A. (r969). F. Endocr. 45, ii.

Hervey, G. R. (1959). F. Physiol., Lond. 145, 336 .

Hervey, G. R. (1962). Excerpta Med. Intern. Cong. Ser, 47, 688.

Hervey, G. R. (1964). Proc. Nutr. Soc. 23, xxii.

Hervey, G. R. (I969a). Nature, Lond. 222, 629.

Hervey, G. R. (1969b). Proc. Nutr. Soc. 28, 54A.

Hervey, G. R. \& Hervey, E. (I964). F. Endocr, 3o, vii.

Hervey, G. R. \& Hervey, E. (1965). F. Endocr. 33, ix.

Janowitz, H. D. \& Hollander, F. (1955). Ann. N.Y. Acad. Sci. 63, 56.

Kennedy, G. C. (1953). Proc. R. Soc. B. 140, 578.

Mayer, J. (1952). Bull. New Engl. med. Cent. 14, 43.

Mayer, J. (1955). Ann. N.Y. Acad Sci. 63, 15.

Miller, D. S., Mumford, P. \& Stock, M. J. (1967). Am. F. clin. Nutr. 20, 1223.

Richter, C. P. (1956). Proceedings of the Second Fosiah Macy Conference p. I I. Baltimore: Josiah Macy Foundation.

Widdowson, E. M., Edholm, O. G. \& McCance, R. A. (r954). Br. F. Nutr. 8, I47.

\section{Metabolic and physical control of food intake in ruminants}

\author{
By J. A. Bines, National Institute for Research in Dairying, Shinfield, \\ Reading $R G 29 A T$
}

\section{Introduction}

Various aspects of the regulation of food intake in ruminants have recently been reviewed by Campling (1970), Baumgardt (1970), Baile \& Mayer (1970) and Arnold (1970) in greater detail than is possible here. This paper will attempt to integrate this information for the housed ruminant, with emphasis on those points of particular interest to the author.

The total amount of food eaten by an animal in a given period of time depends on (I) the number of meals eaten in that time, (2) the length of each meal, (3) the rate of eating during each meal. Factors affecting food intake may operate by changing one or more of these; a change in one may be compensated for by an opposite change in one or both the others. Therefore, it is often important to consider the net effect on the total amount of food eaten in a period of time, which may be different from the effect expected if one of the above were studied in isolation from the others. 